\title{
Oral route of mini-proinsulin-expressing Ganoderma lucidum decreases blood glucose level in streptozocin-induced diabetic rats
}

\author{
TING NI, YUANLEI HU, LI SUN, XI CHEN, JIN ZHONG, HONG MA and ZHHONGPING LIN \\ National Laboratory of Protein Engineering and Plant Genetic Engineering, \\ College of Life Sciences, Peking University, 100871 Beijing, P.R. China
}

Received March 30, 2007; Accepted May 3, 2007

\begin{abstract}
Oral administration of insulin to control blood glucose has become a hot area of diabetes research. The major issue is to produce enough insulin and prevent insulin degradation in the acidic environment of the stomach. We hypothesize that the natural structure of the cell wall and the endoplasmic reticulum in Ganoderma lucidum should help resist the digestion of insulin produced in these cells, making this fungus a feasible production and a new delivery system for oral insulin. A new mini-proinsulin gene was constructed and was transformed into G. lucidum by the Agrobacteriummediated method. Driven by a strong promoter of GPD isolated from Lentinus edodes, expression of mini-proinsulin reached $\leq 10.4 \%$ of total soluble protein, equal to $174 \mu \mathrm{g} / \mathrm{g}$ wet weight, which is sufficient for oral route. Oral route of transgenic G. lucidum significantly reduced blood glucose in streptozocininduced diabetic rats, as compared to rats fed with saline $(\mathrm{P}<0.0002)$ or non-transgenic G. lucidum $(\mathrm{P}<0.0002)$. Blood glucose was reduced $\leq 64 \%$ in $80 \%$ of diabetic rats. Evaluation of pancreatic pathology showed that $54.5 \%$ rats in the transgenic group had no pathological changes, as compared to $25 \%$ in the saline group and $33.3 \%$ in the non-transgenic group. Rats in transgenic group had insulitis score $<2$, while $30 \%$ of rats in the saline group had insulitis score $>2$. These experimental results indicate that oral route of mini-proinsulinexpressing $G$. lucidum can be used to control blood glucose in diabetes and to improve pancreatic cell function.
\end{abstract}

\section{Introduction}

Diabetes is a group of serious diseases characterized by high blood glucose levels that result from defects in the body's

Correspondence to: Professor Zhongping Lin, National Laboratory of Protein Engineering and Plant Genetic Engineering, College of Life Sciences, Peking University, 100871 Beijing, P.R. China E-mail: linzp@pku.edu.cn

Abbreviations: G. lucidum, Ganoderma lucidum; GPD, glyceraldehyde-3-phosphate dehydrogenase; TSP, total soluble protein; STZ, streptozocin

Key words: oral route, mini-proinsulin, G. lucidum, blood glucose ability to produce and/or use insulin (1), which is the only hormone in the body to decrease blood glucose level. Oral insulin has elicited overwhelming interest and investment in recent years because of its advantage of no pain comparing to insulin injection (2-4).

Five alternative strategies of oral insulin delivery have emerged, including penetration enhancers (5), intestinal coating (6), protease inhibitors (7), colon site-specific delivery (8), and insulin microspheres $(9,10)$. The key issue of all these strategies is to prevent insulin degradation in the acidic environment of the stomach and digestive environment in the small intestine. However, all these strategies have a high cost because of the need of commercial insulin. Herein for the first time, we provide a new cheaper strategy of oral insulin, using transgenic G. lucidum, the traditional Chinese medical mushroom, to produce enough mini-proinsulin with the growing mycelia of fungus.

Three different ways were applied to increase the expression level of mini-proinsulin in G. lucidum. Because of the similarity of codon preference between fungus and plant, mini-proinsulin was synthesized based on plant bias codon (11). In order to find a strong promoter to drive the mini-proinsulin gene, we used promoter deletion analysis to optimize the GPD (glyceraldehyde-3-phosphate dehydrogenase) promoter derived from Lentinula edodes, another edible fungus (12). KDEL sequence (13), which can greatly enhance retention of heterologous proteins in the ER and thus leads to the increased stability and higher level of accumulation of heterologous proteins, was also added to the C-terminal end of mini-proinsulin. In this study, oral route of the transformed mycelia sufficiently reduced blood glucose levels in streptozocin (STZ)-induced diabetic rats, indicating the potential use of mini-proinsulin-expressing G. lucidum as an efficient strategy for oral insulin delivery.

\section{Materials and methods}

Construct of the mini-proinsulin gene. Double-stranded DNA was synthesized to construct $180 \mathrm{bp}$ of the mini-proinsulin gene. The B-chain and the A-chain of human insulin was designed and constructed based on plant codon preference, and both chains were connected to an ORF by a 6-AA sequence of GGPSGG, which has the corresponding nucleotide sequence 'GGA GGA CCA TCT GGA GGA'. The initiation code 'ATG' was added before the B-chain, the stop 
code 'TAA' was added to the end of the A-chain, and the restriction enzyme sites BamHI and EcoRI were added to the beginning and the end of the constructed gene respectively. To direct intracellular retention of mini-proinsulin protein, the KDEL sequence (AAG GAC GAG CTT) was added before the stop code 'TAA', resulting in the modified miniproinsulin gene Ins $K$. Sequencing of the InsK gene was performed to confirm the construction.

Construct of the G. lucidum expression vector p1300-GinsK. The mini-proinsulin gene InsK was inserted into pGEM-11Z. A 1.4-kb fragment of the PLeGPD promoter isolated from HindIII-BamHI digested pL221 was inserted into HindIIIBamHI digested pGEM11Z-InsK, and the resulting plasmid was named pLInsK. A $1.6 \mathrm{~kb}$ of GPD-InsK fragment isolated from HindIII-Sac I digested pLInsK was inserted into pL321b digested with the same enzymes, resulting in the plasmid pbInsK. A $3.4 \mathrm{~kb}$ HindIII-KpnI fragment of pbInsK was linked to HindIII-KpnI digested p1300-Super-PAnos to obtain the final construct of the expression vector p1300GInsK.

Agribacterium-mediated transformation of G. lucidum. G. lucidum was cultured in $500 \mathrm{ml}$ of CYM medium (1\% maltose, $2 \%$ glucose, $0.2 \%$ yeast extract, $0.2 \%$ tryptone, $0.05 \% \mathrm{MgSO}_{4} \cdot 7 \mathrm{H}_{2} \mathrm{O}, 0.46 \% \mathrm{KH}_{2} \mathrm{PO}_{4}$ ) at $28^{\circ} \mathrm{C}$ for $4-5$ days. Glass balls were used to distribute the mycelia by agitating twice a day. The expression vector p1300-GInsK was transferred into the Agrobacterium strain LBA4404, which was then cultured overnight at $28^{\circ} \mathrm{C}$ at $250 \mathrm{r} / \mathrm{min}$. AS was added on the second day with a final concentration of $200 \mu \mathrm{mol} / 1$, and Agrobacterium was cultured until the $\mathrm{OD}_{660}$ reached 0.6-0.8. Mycelia of G. lucidum was collected by filtration through four layers of sterile gauze, rinsed 4 or 5 times with sterile water, and suspended in $1 \mathrm{ml}$ of sterile water. Suspended mycelia $(100 \mu 1)$ was mixed with $100 \mu 1$ of LBA4404 carrying p1300-GInsK, and cultured at $28^{\circ} \mathrm{C}$ for 2 days on CYM solid medium containing 1\% Agrose. CYM selective medium (10 ml: $20 \mu \mathrm{g} / \mathrm{ml}$ PPT and $500 \mu \mathrm{g} / \mathrm{ml} \mathrm{Cb}$ was added to CYM solid medium) was added to the top of the CYM solid medium. The plate was cultured at $28^{\circ} \mathrm{C}$ for another 7-10 days until white regenerative colonies appeared.

PCR procedure and Northern blot analysis. SDS protocols were used to extract total DNA from G. lucidum. Briefly, mycelia of $G$. lucidum was filtered through two layers of gauze, rinsed with distilled water, and dried in filter paper. Mycelia (0.1 g wet) was collected into $1.5-\mathrm{ml}$ eppendorf tube, frozen in liquid nitrogen and grounded in a glass pestle. DNA extraction buffer was composed of $50 \mathrm{mM}$ EDTA, 0.5 $\mathrm{M} \mathrm{NaCl}, 1.5 \%$ SDS, $1 \%$ (v/v) B-mercaptoethanol, and $0.1 \mathrm{M}$ Tris-HCl, $\mathrm{pH}$ 8.0. The TRIzol method was used to extract total RNA from G. lucidum. To amplify the InsK DNA fragment, the following primers were used: Forward primer: 5'-GTT AAC CAA CAC CTT TGC GGA T-3', Reverse primer: 5'-GAG AGC AGA TAG AGG TGC AGC A-3'; and 30 cycles of PCR amplification were done at $94^{\circ} \mathrm{C}$ for $30 \mathrm{sec}$, $50^{\circ} \mathrm{C}$ for $30 \mathrm{sec}$, and $72^{\circ} \mathrm{C}$ for $30 \mathrm{sec}$. Another pair of primers was used to amplify the GPD-InsK fragment: Forward primer: 5'-ACC AAG AAA GCT CGT GAA GAG G-3',
Reverse primer: 5'-CCG CAA ACA AGG TAA AGA GCC-3', and 30 cycles of PCR amplification was done at $94^{\circ} \mathrm{C}$ for $50 \mathrm{sec}, 50^{\circ} \mathrm{C}$ for $50 \mathrm{sec}$, and $72^{\circ} \mathrm{C}$ for $50 \mathrm{sec}$. Northern blot analysis was conducted based on the digoxigenin-labeled method.

Western blot analysis and ELISA test. To extract total protein, $50 \mathrm{mg}$ of mycelia frozen in liquid nitrogen was ground, $500 \mu 1$ of extraction buffer (0.1 M PBS, $0.001 \%$ $\mathrm{NaN}_{3}, 0.00029 \%$ PMSF) was added to the mycelia powder, the extraction was centrifuged at $12,000 \mathrm{rpm}$ for $5 \mathrm{~min}$, and the supernatant was used for Western blotting and ELISA. Insulin standards (Sigma) were the recombinant human insulin expressed in yeast. Rabbit anti-mini-proinsulin serum (1:10000, antigen was made in glutaraldehyde cross-linked mini-proinsulin expressed in the pET system) and goat antirabbit IgG-AP (1:1000, Bioss) were used in Western blotting. Guinea pig anti-human insulin $(1: 100$, China Institute of Atomic Energy, Isotope Institute) and goat anti-guinea pig IgG-HRP (1:2000, Bioss) were used in the ELISA test.

STZ-induced diabetic rats and treatment with transgenic $G$. lucidum. SD rats (48 male) weighting $\sim 250 \mathrm{~g}$ were used for animal experiments. Diabetes was induced by a single intraperitoneal injection of STZ (60 mg/kg body weight of rat). Seven days after the STZ injection, diabetes onset was evaluated by monitoring blood glucose in rats fasted for $8 \mathrm{~h}$. The rats were considered as diabetic, if the blood glucose level was $>14 \mathrm{mmol} / \mathrm{l}$. Mycelia sphere of G. lucidum was processed in a juicer device, and $6 \mathrm{ml}$ of mycelia preparation was injected into the stomach. Thirty diabetic rats were selected and evenly divided into three groups comprising of 10 animals in each group as follows: saline group (fed with $6 \mathrm{ml} \mathrm{0.9 \%} \mathrm{NaCl}$ ), non-transgenic group (fed with $6 \mathrm{ml}$ mycelia preparation of non-transgenic G. lucidum), and transgenic group (fed with $6 \mathrm{ml}$ mycelia preparation of transgenic $G$. lucidum). Blood glucose levels were tested 4 and $20 \mathrm{~h}$ after the treatment.

Pancreatic pathology and degree of insulitis. Diabetic rats were fed with $6 \mathrm{ml}$ of saline or mycelia preparation once a week for 4 weeks. One week after the last feeding, the rats from each group were sacrificed for the analysis of pancreatic pathology. Pancreas tissues were removed and fixed in $10 \%$ formalin, stained with hematoxylin and eosin (H\&E), sectioned at nonoverlapping levels, and imaged with x20 optical microscope. Pancreatic pathology was evaluated as follows: 0 , normal islet with no pathological changes; 0.5 , suspicious pathological changes; 1 , slight changes; 2 , medium changes; 3 , severe changes. Degree of insulitis was scored as follows: 0 , normal islet with no sign of $\mathrm{T}$ cell infiltration; 1 , islet associated with perivascular, periductal leukocytic infiltration only; 2 , more extensive peri-islet infiltration, but with lymphocytes with $<50 \%$ islet destruction; $3,>50 \%$ islet destruction.

\section{Results}

Construct of the mini-proinsulin gene. The B chain and A chain of the insulin gene were designed based on the sequence of the human insulin gene (GenBank GI: 69307). Amino acids 
A

\section{GATCOATGIT CGTTAACCAA CACCITTGCG GATCTCACCT TGITGAGGCT GTADAA GCAATTGGTT GTGGAAACGC CTAGAGTGGA ACAACTCCGA BamHI \\ Insulin B-chain}

51 CITTACCTTG TTTGCGGAGA GAGGGGATTC TTCTACACCC CAAAGACCGG GAAATGGAAC AAACGCCTCT CTCCCCTAAG AAGATGTGGG GITTCTGGCC (Insulin B-chain) Gly

101 AGGACCATCT GGAGGAGGAA TCGITGAGCA ATGCTGCACC TCTATCTGCT TCCTGGTAGA CCTCCTCCTI AGCAACTCGI TACGACGTGG AGATAGACGA Gly Pro Ser Gly Gly Insulin A-chain

151 CTCTTTACCA ACTIGAGAAC TACTGCAACA AGGACGAGCT IT AAC GAGAAATGGT TGAACTCTTG ATGACGTTGI TCCTGCTCGA AA TTCTTAA (Insulin A-chain) KDEL stop codon EcoRI

B

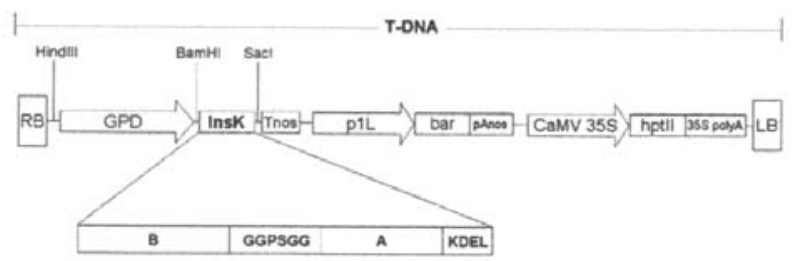

Figure 1. Coding sequence of mini-proinsulin gene and its T-DNA region. (A) The InsK gene with plant preference codon. KDEL: ER retention signal. (B) T-DNA region of fungi expression vector p1300-GInsK. RB and LB: the right and left T-DNA borders; GPD: the glyceraldehyde-3-phosphate dehydrogenase promoter of L. edodes; Tnos and pAnos: polyadenylation signals from nopaline synthase; p1L: core region of GPD promoter; bar: PPT acetyltransferase gene provides PPT resistance in G. lucidum; CaMV 35S: cauliflower mosaic virus 35S promoter; $h p t I I$ : hygromycin phosphotransferase II gene providing hygromycin resistance in G. lucidum; 35S polyA: polyadenylation signals from cauliflower mosaic virus $35 \mathrm{~S}$ gene; InsK: designed mini-proinsulin gene; $\mathrm{B}$ : CDS for the B-chain of human insulin; A: CDS for the A-chain of human insulin; GGPSGG: linker peptide of six amino acids.

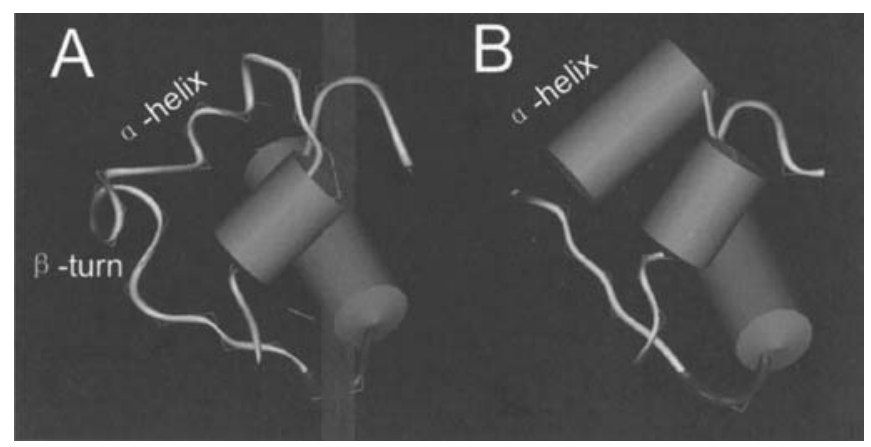

Figure 2. Secondary structure of mini-proinsulin comparing with natural human insulin. (A) Secondary structure prediction of mini-proinsulin using TopPred 2 software. (B) Secondary structure of natural human insulin.

in the B chain and A chain were optimized based on plant codon preference. A short chain (GGPSGG) was added to connect the B chain and the A chain. The initiation code ATG was added to the $\mathrm{B}$ chain and the termination code TAA was added to the A chain. The KDEL sequence was added to the $\mathrm{C}$-terminal of the A chain. The resulting gene was named mini-proinsulin gene, InsK (Fig. 1A). The InsK gene was then inserted to the pGEM-11Z vector. Gene sequencing was performed to confirm the sequence of the constructed InsK

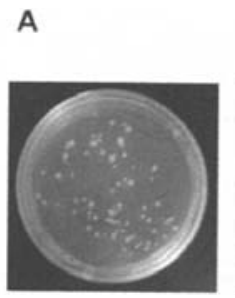

B

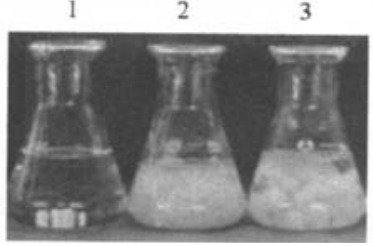

C

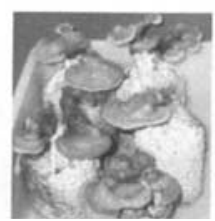

Figure 3. Selection of PPT resistance in transgenic G. lucidum. (A) Regeneration of $G$. lucidum mycelia in PPT selective CYM plate using Agribacterium-mediated transformation. (B) Mycelia growth in PPT selective CYM liquid medium. Lane 1: non-transgenic G. lucidum; lanes 2-3: transgenic lines of G. lucidum. (C) Fruit body of transgenic G. lucidum.
A
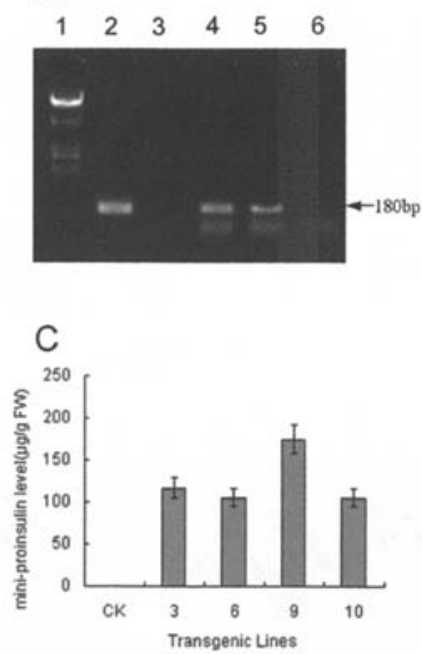

B
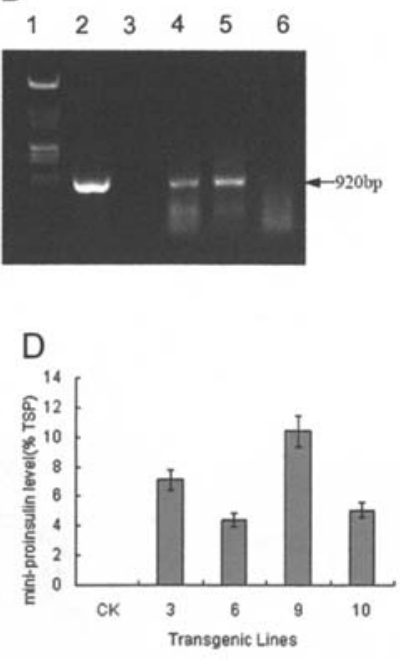

Figure 4. Molecular analysis of the InsK gene in transgenic G. lucidum. (A) PCR detection of Ins $K$ fragment in transgenic G. lucidum. (B) PCR detection of GPD-InsK fragment in transgenic G. lucidum. Lane 1: DNA/HindIII+EcoRI Marker; lane 2: InsK gene from fungi expression vector p1300-GInsK; lane 3: $\mathrm{dd}_{2} \mathrm{O}$; lane 4: genomic DNA from transgenic G. lucidum (transgenic line GInsK3); lane 5: genomic DNA from transgenic G. lucidum (transgenic line GInsK6); lane 6: genomic DNA from nontransgenic G. lucidum. (C) Mini-proinsulin level ( $\mu \mathrm{g} / \mathrm{g}$ fresh weight, FW) of different transgenic lines using ELISA detection. (D) Mini-proinsulin level (percent of total soluble protein, TSP) in different transgenic lines using ELISA detection. CK: non-transgenic G. lucidum.

gene. Gene expression vector p1300-GInsK, as its T-DNA region shown in Fig. 1B, was introduced into G. lucidum using the Agribacterium-mediated method. Secondary structure prediction of mini-proinsulin using TopPred 2 software is shown in Fig. 2.

Obtaining the mini-proinsulin-expressing G. lucidum. The InsK gene was introduced into G. lucidum using the Agribacteriummediated method. Transgenic G. lucidum regenerated in CYM selective medium containing $20 \mu \mathrm{g} / \mathrm{ml}$ PPT (Fig. 3A) was transferred into new CYM selective medium (Fig. 3B). Positive transgenic lines of G. lucidum were cultured to obtain the fruit body (Fig. 3C).

Molecular analysis of transgenic G. lucidum. The SDS method was used to isolate total DNA from transgenic G. lucidum, and both InsK gene (Fig. 4A) and GPD-InsK fragment (Fig. 4B) 


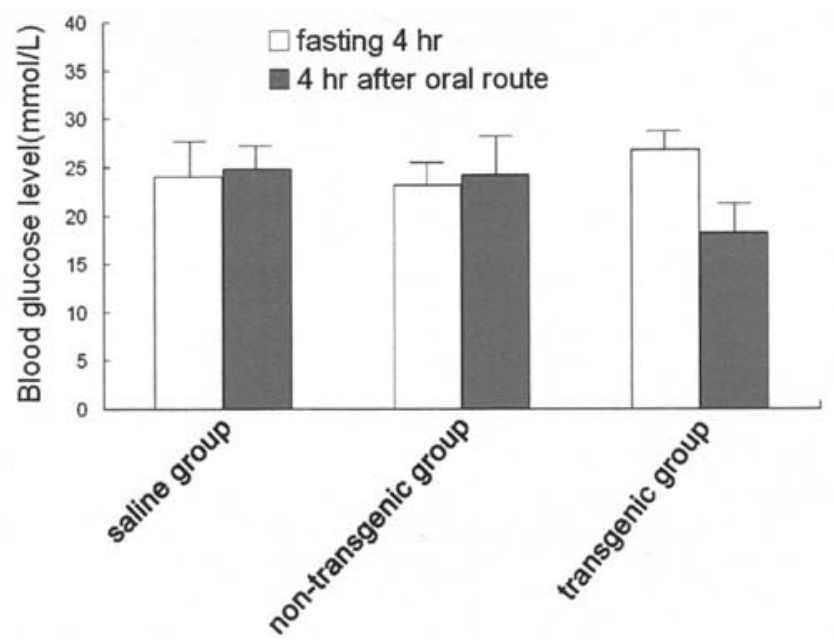

Figure 5. Decrease of blood glucose level by oral route of InsK-transformed G. lucidum in STZ-induced diabetic rats. Each group has 10 rats, fed with $6 \mathrm{ml}$ mycelia preparation or $0.9 \% \mathrm{NaCl}$ after $4 \mathrm{~h}$ fasting. There is no significant change of blood glucose level $4 \mathrm{~h}$ after oral route of saline solution $(\mathrm{P}=0.311$; Student's t-test), or the non-transgenic group $(\mathrm{P}=0.210$; Student's t-test). Blood glucose level is substantially decreased $4 \mathrm{~h}$ later after oral route administration of transgenic G. lucidum $(\mathrm{P}<0.0002$; Student's t-test).

was detected by PCR. InsK mRNA was detected by Northern blotting (figure not shown), and protein expression of InsK was shown by Western blotting (figure not shown). Insulin standards (Sigma) were used in ELISA to detect the level of mini-proinsulin in transgenic G. lucidum. The mini-proinsulin protein levels were between 105.0 and $174.8 \mu \mathrm{g} / \mathrm{g}$ wet weight
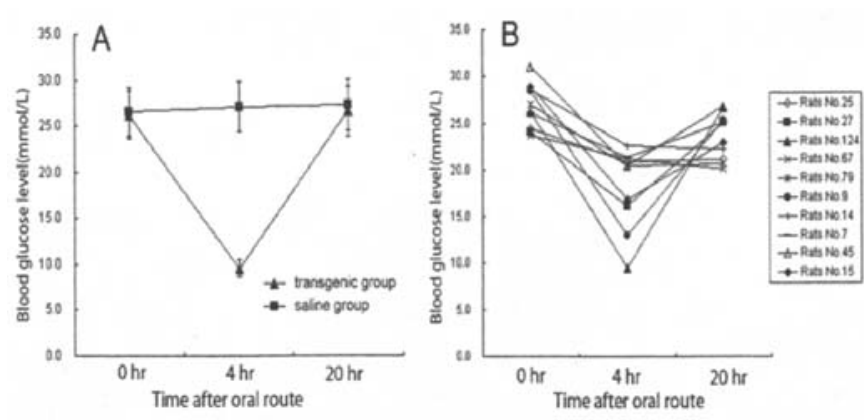

Figure 6. Time course of blood glucose after oral route administration of transgenic G. lucidum. (A) Blood glucose level of No. 124 rat in transgenic group comparing with No. 35 rat in $0.9 \% \mathrm{NaCl}$ group. (B) Blood glucose level of diabetic rats in the transgenic group after oral route of transgenic $G$. lucidum.

of filamentous fungi (Fig. 4C), and reached 4.4-10.4\% of total soluble proteins (Fig. 4D).

Short-term effect of transgenic G. lucidum in STZ-induced diabetic rats. In separate groups, saline solution, non-transgenic G. lucidum, or transgenic G. lucidum were fed to the STZinduced diabetic rats. Four hours after the administration, blood glucose levels had no significant change in the saline or the non-transgenic group, as shown in Fig. 5. In contrast, blood glucose levels were significantly decreased $4 \mathrm{~h}$ after oral route of transgenic G. lucidum in STZ-induced diabetic rats $(\mathrm{P}<0.0002$; Student's test $)$. The result indicates that mini-

Table I. Pancreatic pathology in STZ diabetic rats.

\begin{tabular}{lccc}
\hline $\begin{array}{l}\text { Degree of } \\
\text { pathology }\end{array}$ & $\begin{array}{c}\text { No. of rats in the } \\
\text { saline group }\end{array}$ & $\begin{array}{c}\text { No. of rats in the } \\
\text { transgenic group }\end{array}$ & $\begin{array}{c}\text { No. of rats in the } \\
\text { non-transgenic group }\end{array}$ \\
\hline 0 & 3 & 6 & 4 \\
0.5 & 3 & 2 & 2 \\
1 & 1 & 1 & 3 \\
2 & - & 2 & 2 \\
3
\end{tabular}

0, normal islet with no pathological changes; 0.5 , suspicious pathological changes; 1 , slight changes; 2 , medium changes; 3 , severe changes.

Table II. Degree of insulitis in STZ diabetic rats.

\begin{tabular}{lccc}
\hline $\begin{array}{l}\text { Degree of } \\
\text { insulitis }\end{array}$ & $\begin{array}{c}\text { No. of rats in the } \\
\text { saline group }\end{array}$ & $\begin{array}{l}\text { No. of rats in the } \\
\text { transgenic group }\end{array}$ & $\begin{array}{c}\text { No. of rats in the } \\
\text { non-transgenic group }\end{array}$ \\
\hline 0 & 2 & 5 & 6 \\
1 & 5 & 5 & 6 \\
2 & 3 & - & - \\
3 & - & - & - \\
\hline
\end{tabular}

0 , normal islet with no sign of T cell infiltration; 1 , islet associated with perivascular, periductal leukocytic infiltration only; 2 , more extensive periislet infiltration, but with lymphocytes with $<50 \%$ islet destruction; $3,>50 \%$ islet destruction. 


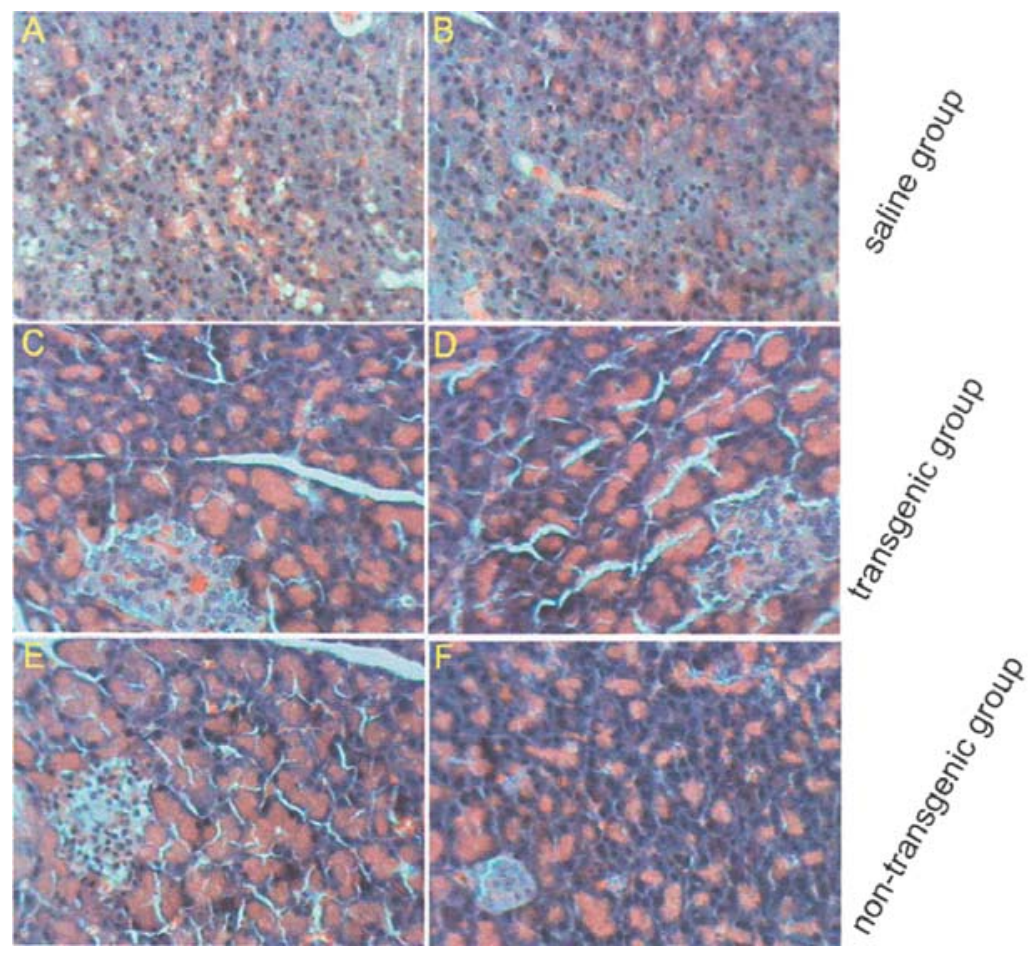

Figure 7. Histological analysis of pancreatic islets from STZ rats. Four weeks after the weekly oral route administration, pancreatic sections from STZ rats were stained with standard H\&E stain and imaged under a x20 light microscope. (A and B) Rats \#2 and \#35 in the saline group. Pancreatic islets displayed extensive damage, intact islets with secretory cells rich in cytoplasm were absent, and only few infiltrations marked the sites of islets. (C and D) Rats \#15 and \#27 in the transgenic group. (E and F) Rats \#6 and \#39 in the non-transgenic group. Intact healthy islets contained normal secretory cells rich in cytoplasm.
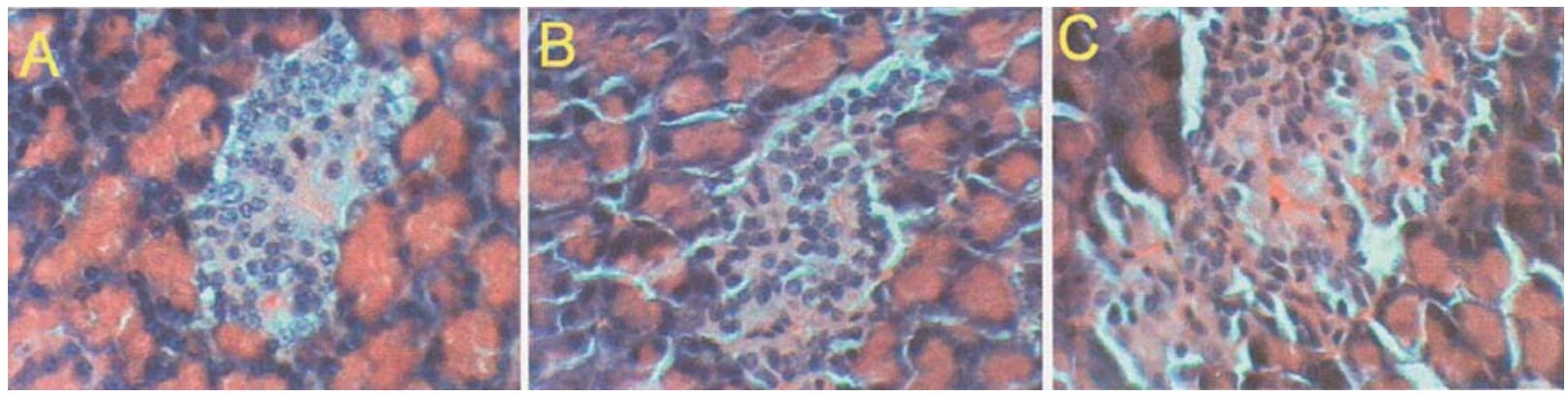

Figure 8. Histological analysis of insulitis. Four weeks after the weekly oral route, pancreatic pathology was evaluated by H\&E stain under a x20 light microscope. Degree of insulitis was scored 0 (A), 1 (B), and 2 (C). (A) Transgenic group; normal islet with no pathological changes. (B) Non-transgenic group; islet associated with perivascular, periductal leukocytic infiltration only. (C) Saline group; more extensive peri-islet infiltration, but with lymphocytes with $<50 \%$ islet destruction.

proinsulin expressed in the transgenic G. lucidum take its biological effect of down-regulation of the blood glucose level in vivo.

Long-term effect of transgenic G. lucidum in STZ-induced diabetic rats. As shown in Fig. 6A, blood glucose levels were compared between rats \#35 and \#124. In rat \#35, which received saline, blood glucose levels remained unchanged from the baseline up to $20 \mathrm{~h}$. In rat $\# 124$, which received transgenic G. lucidum, blood glucose level decreased by $64 \%$ below baseline in $4 \mathrm{~h}$, subsequently returning to baseline in 20 h. As shown in Fig. 6B, significant reduction of blood glucose levels were observed in $80 \%$ of diabetic rats in the transgenic group, with the highest reduction of $64 \%$.
Attenuation of pancreatic pathology by oral route of transgenic G. lucidum. The long-term effect of transgenic G. lucidum on pancreatic pathology was evaluated after 4 weeks of weekly oral route administration. Absence of pathological changes were observed in $54.5 \%$ of diabetic rats in the transgenic group, compared to $33.3 \%$ in the non-transgenic and $25 \%$ in the saline groups. Corresponding rates of severe pathological changes were 18.2, 16.7 and 41.7\% (Table I). Pathological changes were evaluated through photomicrograph of pancreatic tissue (original magnification, x25; H\&E stain). Large areas of hemorrhage were found in pancreatic tissue of the saline group; moreover, the acinar structure was obscure and there were large areas of necrosis, nuclear lysis, and the presence of saponified spots (Fig. 7A and B). In contrast, 
intact healthy islets with normal secretory cells rich in cytoplasm were observed in both transgenic and nontransgenic groups (Fig. 7C-F). Since non-transgenic $G$. lucidum also ameliorated pancreatic pathology, we speculate that G. lucidum, a traditional Chinese medicine, may play a curative role by improving the immune system. This is also the reason we chose G. lucidum as the transgenic target. We expected that oral route of G. lucidum transformed with the mini-proinsulin gene would not only reduce blood glucose in the short-term but also relieve pancreatic pathology in the long-term.

Inhibition of insulitis by oral route of transgenic G. lucidum. To determine the degree of pathology, we graded insulitis on an ascending scale of 0-5. Only $20 \%$ of rats in the saline group had a grade of 0 (Fig. $8 \mathrm{~A}$ ); in contrast, $50 \%$ of the rats in both the transgenic and non-transgenic group had grade of 0 (Table II). In addition, $50 \%$ of the rats in all three groups had a grade of 1 (Fig. 8B); $30 \%$ of the rats in the saline group had a grade of 2 (Fig. 8C), which was not observed in either the transgenic or non-transgenic group (Table II). These results suggest that both transgenic and non-transgenic G. lucidum can inhibit insulitis to some extent.

\section{Discussion}

Although it was demonstrated by Arakawa et al that oral administration of transgenic potato tubes expressing CTBinsulin can reduce the occurrence of diabetes in type I diabetes in NOD mice $(14,15)$, there are two major advances in our study. Firstly, the expression level of mini-proinsulin reached $\leq 10.4 \%$ of total soluble protein, equal to $174 \mu \mathrm{g} / \mathrm{g}$ wet weight, which is far more than the level $\leq 0.05 \%$ of total soluble protein in potato tubes (14). Secondly, oral route of transgenic G. lucidum decreased the blood glucose level in $4 \mathrm{~h}$ and attenuated pancreatic pathology and inhibited insulitis in 4 weeks, while oral route of transgenic potato tubes inhibited insulitis in 30 weeks (14).

Higher fungus such as G. lucidum is a good bioreactor to produce therapeutic proteins; it is well known only for its natural forms in potential medical function (16-18). In addition to its original medical usage and advantage of no side effects, transgenic G. lucidum is also a new strategy of oral insulin. Our experimental design was to use G. lucidum to deliver both the exogenous mini-proinsulin and other natural medicinal contents of this fungus to treat diabetes. As a long-used medicinal fungus, G. lucidum has shown various effects in enhancing the immune system, inhibiting tumors, and improving diabetes (16-18).

High expression of mini-proinsulin in G. lucidum is a critical prerequisite for its direct effects on down-regulation of blood glucose and oral immune tolerance. The Agrobacterium-mediated method in the transformation of $G$. lucidum was not been reported previously, although $G$. lucidum has been successfully transformed by other methods, such as electroporation and restriction enzyme-mediated integration $(12,19)$. For the first time, a new method of Agrobacterium-mediated gene transformation was developed based on the method applied in Trichoderma Harzianum. While spores were used as the transgenic target in $T$.
Harzianum, the filamentous fungus was used to transform $G$. lucidum (20).

The human mini-proinsulin is characterized by a C-chain peptide consisting of only 9 amino acids (21-24), whereas the C-chain peptide of natural human proinsulin is made up of 35 amino acids. The bridge between $B$ chain and A chain is only $16.12 \AA$, and $16 \AA$ is the minimum distance between a five-AA protein; hence, a three to five amino acid should be able to connect the $\mathrm{C}$ terminal $\mathrm{B}$ chain and the $\mathrm{N}$ terminal $\mathrm{A}$ chain, forming a modified protein which has the same function as natural insulin. The advantage of using the mini-proinsulin gene is that the A-chain and the B-chain of the insulin gene can be expressed in one ORF, and that the short substituting $\mathrm{C}$-peptide made the structure of mini-proinsulin more like insulin. We need to point out that $\beta$-turn structure was taken into serious consideration in the design of our linking peptide. Different amino acids have various preferences and capabilities in forming the second structure. While Pro and Gly barely form $\alpha$-helix and $\beta$-sheet, $\beta$-turns are common structures in Pro, Gly, Asn and Ser $(25,26)$, suggesting that $\beta$ turns can be easily formed in Gly-Pro-Ser. Therefore, we chose Gly-Gly-Pro-Ser-Gly-Gly as the linking peptide.

Under the new concept of insulin coating, mini-proinsulin was not only produced within the cells, but also protected by the natural structure of the cell wall, plasma membrane, and endoplasmic rectum. Therefore, expressing mini-proinsulin in the bioreactor G. lucidum provides a novel strategy in oral administration of insulin. In contrast to the CTB-INS fusion protein expressed in transgenic potato plants (14), transgenic G. lucidum significantly reduced blood glucose in diabetic rats within $4 \mathrm{~h}$ of oral administration, and it attenuated the pancreatic tissue pathological changes and insulitis in STZinduced diabetic rats after 4 weeks of oral administration. These experimental results provide a new direction for the treatment of diabetes.

\section{Acknowledgements}

We would like to thank A. Kang (Department of Medical Laboratory, Animal Science Department of Beijing University) for preparation of STZ diabetic rats and blood glucose test, Professor D. Zhao (Animal Research Institute, China Agricultural University) and L. Yang for helping in the evaluation of pancreatic pathology and degree of insulitis, and Professor J. Bhattacharya (Department of Physiology and Cellular Biophysics, Columbia University) for helping with the language improvement.

\section{References}

1. Atkinson MA and Maclaren NK: The pathogenesis of insulindependent diabetes mellitus. N Engl J Med 331: 1428-1436, 1994.

2. Bergenstal RM: Treatment models from the international diabetes center: advancing from oral agents to insulin therapy in type 2 diabetes. Endocr Pract 12 (Suppl 1): 98-104, 2006.

3. Bergerot I, Fabien N, Maguer V and Thivolet C: Oral administration of human insulin to NOD mice generates CD4 ${ }^{+} \mathrm{T}$ cells that suppress adoptive transfer of diabetes. J Autoimmun 7: 655-663, 1994.

4. Bergerot I, Fabien N, Mayer A and Thivolet C: Active suppression of diabetes after oral administration of insulin is determined by antigen dosage. Ann NY Acad Sci 778: 362-367, 1996. 
5. Jederstrom G, Grasjo Nordin A, Sjoholm I and Andersson A: Blood glucose-lowering activity of a hyaluronan-insulin complex after oral administration to rats with diabetes. Diabetes Technol Ther 7: 948-957, 2005.

6. Morishita M, Morishita I, Takayama K, Machida Y and Nagai T: Site-dependent effect of aprotinin, sodium caprate, $\mathrm{Na}_{2} \mathrm{EDTA}$ and sodium glycocholate on intestinal absorption of insulin. Biol Pharm Bull 16: 68-72, 1993.

7. Yamamoto A, Taniguchi T and Rikyuu K: Effects of various protease inhibitors on the intestinal absorption and degradation of insulin in rats. Pharm Res 11: 1496-1500, 1994.

8. Tozaki H, Nishioka J, Komoike J, Okada N, Fujita T, Muranishi S, Kim SI, Terashima H and Yamamoto A: Enhanced absorption of insulin and (Asu(1,7))eel-calcitonin using novel azopolymercoated pellets for colon-specific dr $\mu$ g delivery. J Pharm Sci 90: 89-97, 2001.

9. Carino GP, Jacob JS and Mathiowitz E: Nanosphere based oral insulin delivery. J Controlled Release 65: 261-269, 2000.

10. Wu ZH, Ping QN, Wei Y and Lai JM: Hypoglycemic efficacy of chitosan-coated insulin liposomes after oral administration in mice. Acta Pharmacol Sin 25: 966-972, 2004.

11. Murray EE, Lotzer J and Eberle M: Codon usage in plant genes. Nucleic Acids Res 17: 477-498, 1989.

12. Sun L, Cai HQ, Xu WH, Hu YL, Gao Y and Lin ZP: Efficient transformation of the medicinal mushroom G. lucidum. Plant Mol Biol Reporter 19: 383a-383j, 2001

13. Wandelt CI, Khan MR, Craig S, Schroeder HE, Spencer D and Higgins TJ: Vicilin with carboxy-terminal KDEL is retained in the endoplasmic reticulum and accumulates to high levels in the leaves of transgenic plants. Plant J 2: 181-192, 1992.

14. Arakawa T, Yu J, Chong DK, Hough J, Engen PC and Langridge WH: A plant-based cholera toxin B subunit-insulin fusion protein protects against the development of autoimmune diabetes. Nat Biotechnol 16: 934-938, 1998.

15. Gong Z, Jin Y and Zhang Y: Oral administration of a cholera toxin B subunit-insulin fusion protein produced in silkworm protects against autoimmune diabetes. J Biotechnol 119: 93-105, 2005.

16. Hu H, Ahn NS, Yang X, Lee YS and Kang KS: G. lucidum extract induces cell cycle arrest and apoptosis in MCF-7 human breast cancer cell. Int J Cancer 102: 250-253, 2002.
17. Kino K, Yamashita A, Yamaoka K, Watanabe J, Tanaka S, Ko K, Shimizu K and Tsunoo H: Isolation and characterization of a new immunomodulatory protein, ling zhi-8 (LZ-8), from Ganoderma lucidium. J Biol Chem 264: 472-478, 1989.

18. Kino K, Mizumoto K, Sone T, Yamaji T, Watanabe J, Yamashita A, Yamaoka K, Shimizu K, Ko K and Tsunoo H: An immunomodulating protein, Ling Zhi-8 (LZ-8) prevents insulitis in non-obese diabetic mice. Diabetologia 33: 713-718, 1990.

19. Kim S, Song J and Choi HT: Genetic transformation and mutant isolation in G. lucidum by restriction enzyme-mediated integration. FEMS Microbiol Lett 233: 201-204, 2004.

20. Gao XX, Yang Q, Song JZ and Guo ZK: Agrobacterium tumefaciens-mediated transformation of trichoderma harzianum. High Tech Lett 15: 32-35, 2004.

21. Shin CS, Hong MS, Bae CS and Lee J: Enhanced production of human mini-proinsulin in fed-batch cultures at high cell density of Escherichia coli BL21(DE3)(pET-3aT2M2). Biotechnol Prog 13: 249-257, 1997.

22. Thim L, Hansen MT and Sorensen AR: Secretion of human insulin by a transformed yeast cell. FEBS Lett 212: 307-312, 1987.

23. Chang SG, Kim DY, Choi KD, Shin JM and Shin HC: Human insulin production from a novel mini-proinsulin which has high receptor-binding activity. Biochem J 329: 631-635, 1998.

24. Pais-Chanfrau JM, Garcia Y, Licor L, Besada V, Castellanos-Serra L, Cabello CI, Hernandez L, Mansur M, Plana L, Hidalgo A, et al: Improving the expression of miniproinsulin in Pichia pastoris. Biotechnol Lett 26: 1269-1272, 2004.

25. Perczel A, Jakli I and Csizmadia IG: Intrinsically stable secondary structure elements of proteins: a comprehensive study of folding units of proteins by computation and by analysis of data determined by X-ray crystallography. Chemistry 9: 5332-5342, 2003.

26. Yang AS, Hitz B and Honig B: Free energy determinants of secondary structure formation: III. beta-turns and their role in protein folding. J Mol Biol 259: 873-882, 1996. 